\title{
Cerebellar nodulus infarction secondary to vertebral artery dissection
}

\author{
Sean Lance, ${ }^{\oplus 1}$ Tom Thomson $^{2}$
}

'Department of Medicine, University of Otago Wellington, Wellington, New Zealand ${ }^{2}$ Hutt Valley District Health Board, Lower Hutt, New Zealand

\section{Correspondence to}

Dr Sean Lance,

Sean.Lance@ccdhb.org.nz

Accepted 13 April 2019

\section{DESCRIPTION}

A 40-year-old man with a 5-day history of posterior headache and neck discomfort presented with acute onset severe ataxia when walking across the road causing him to fall. There were no other neurological symptoms. On arrival to the emergency department, his National Institutes of Health Stroke Scale (NIHSS) was assessed as zero due to lack of limb ataxia. He was observed to have left beating horizontal nystagmus and jerky smooth pursuit. His head impulse test was negative, and he was severely ataxic on mobilisation with a tendency to fall to the right.

His medical history was significant for migraine for which he was on amitriptyline $30 \mathrm{mg}$ once a day.

CT head excluded haemorrhage, and CT angiogram revealed a distal vertebral artery dissection with a filling defect immediately proximal to the intracranial extension of the artery consistent with intravascular thrombus (figure 1). The dissected portion of the artery is demonstrated by the change in calibre from the narrow proximal portion to the wider distal portion (compared with the usual situation where the vessel becomes smaller the more
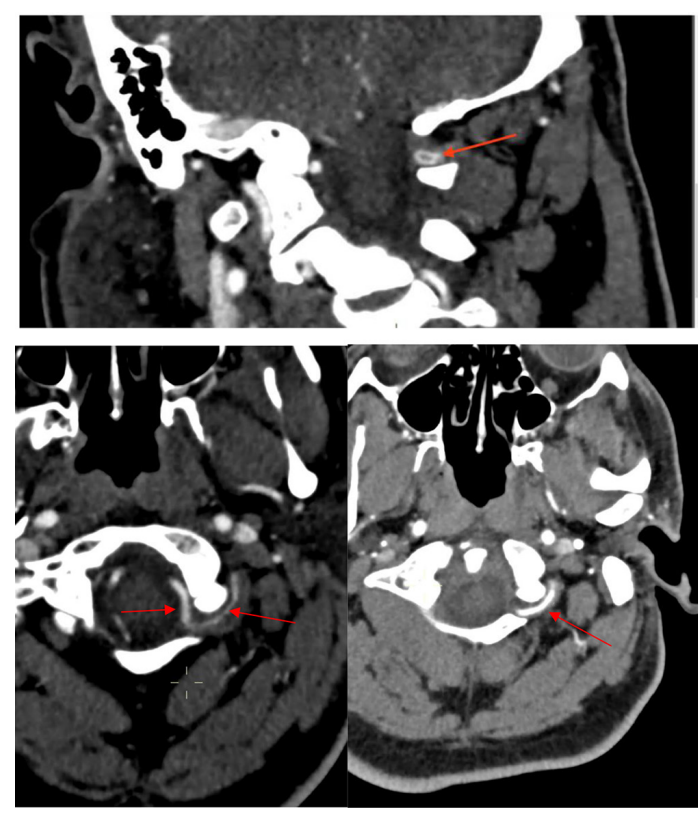

Figure 1 Above: sagittal CT angiogram image showing intravascular clot in left vertebral artery. Left below: left vertebral artery dissection demonstrated by a change in vessel calibre from narrow (proximal, dissected portion) to fully patent (distal, non-dissected portion). Right below: follow up CT angiogram 4 months later demonstrating recanalisation of the left vertebral artery.

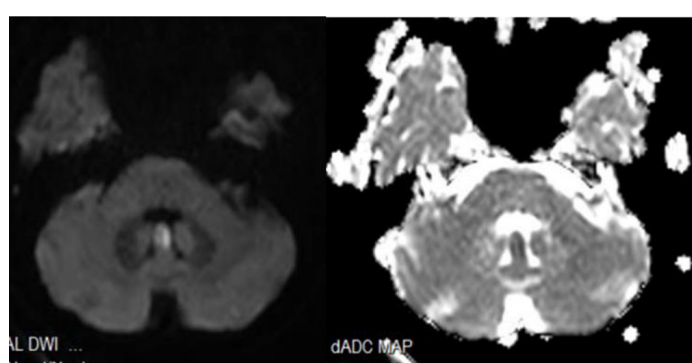

Figure 2 MRI sequences demonstrating acute infarction of the cerebellar nodulus (hyperintense on diffusion weighted imaging (DWI) (left image) with corresponding hypointensity on apparent diffusion coefficient (ADC) (right image)).

distal it travels). Despite an NIHSS of 0 , his ataxia was severe with potentially catastrophic functional impairment so he was thrombolysed with alteplase 2 hours and $58 \mathrm{~min}$ following the onset of symptoms.

An MRI performed the following day revealed an acute infarct of the cerebellar nodulus (figure 2).

$\mathrm{He}$ showed rapid improvement and was discharged home 48 hours after admission, mobilising independently.

Four months later, he was reviewed in clinic with no ongoing neurological deficit. He had been able to return to work as an administrator and was back driving. Repeat CT angiography (figure 1) demonstrated recanalisation of the left vertebral artery.

Isolated infarcts involving the cerebellar nodulus are rare and are challenging to diagnose. The nodulus receives prominent vestibular sensory afferents, and so there is a significant risk of misdiagnosis as typical cerebellar signs are often absent, with the clinical presentation usually more consistent with a vestibular disorder (vertigo and imbalance and the absence of other cerebellar features). ${ }^{1}$ This, along with the relative insensitivity of the NIHSS scoring system to identify suitable patients presenting with posterior circulation stroke syndromes for acute stroke management, results in consistently lower rates of thrombolysis and longer door to needle times. $^{2}$ Olivato et al described an approach (the 'expanded NIHSS' or 'e-NIHSS') which helps to improve posterior circulation stroke sensitivity by modifying the scoring of eye movements to include nystagmus, facial palsy to include palate and tongue deficits and limb ataxia to include postural stability. ${ }^{3}$

The majority of the literature on nodular infarction is restricted to case reports with a small $(n=8$ patients) observational study published in Stroke in 2009 highlighting nodular infarction as a mimic 


\section{Learning points}

- The National Institutes of Health Stroke Score is insensitive for posterior circulation strokes and so a careful assessment of risk factors and clinical features is essential when considering these patients for acute intervention-consider additional examinations

- When presenting with vertigo and/or ataxia, assessment of gait is essential.

of peripheral vertigo. ${ }^{1}$ The key features identified in this paper were the lack of other central features, with vertigo and imbalance most commonly reported. Additionally, features mimicking peripheral vertigo were present including nystagmus ipsilateral to the lesion, with imbalance and falling contralateral to the lesion. ${ }^{1}$ This observation is attributed to disruption of the normal nodular inhibition on the vestibular nucleus and explains the high risk of misdiagnosis in these patients. ${ }^{1}$

Our patient had presented with isolated imbalance, and in the context of his lack of vascular risk factors, a diagnosis of peripheral vertigo seemed most likely. However, as noted, nodulus stroke can present in a similar fashion, and the key aspect of his case was the severe ataxia-so severe he could not stand unaided-not usually such a significant feature in peripheral vestibular disorders.

Our case also highlights the insensitivity of the traditional NIHSS when assessing acute stroke and supports putting a larger emphasis on assessing for significant functional impairment.

Contributors SL was the acute stroke registrar caring for this patient and TT was the Stroke Physician providing acute and ongoing care. SL was the primary author with TT providing advice and editing oversight.

Funding The authors have not declared a specific grant for this research from any funding agency in the public, commercial or not-for-profit sectors.

Competing interests None declared.

Patient consent for publication Obtained.

Provenance and peer review Not commissioned; externally peer reviewed.

\section{REFERENCES}

1 Moon IS, Kim JS, Choi KD, et al. Isolated nodular infarction. Stroke 2009:40:487-91.

2 Merwick Á, Werring D. Posterior circulation ischaemic stroke. BMJ 2014;348:g3175.

3 Olivato S, Nizzoli S, Cavazzuti M, et al. e-NIHSS: an Expanded National Institutes of Health Stroke Scale Weighted for Anterior and Posterior Circulation Strokes. J Stroke Cerebrovasc Dis 2016;25:2953-7.

Copyright 2019 BMJ Publishing Group. All rights reserved. For permission to reuse any of this content visit https://www.bmj.com/company/products-services/rights-and-licensing/permissions/

BMJ Case Report Fellows may re-use this article for personal use and teaching without any further permission.

Become a Fellow of BMJ Case Reports today and you can:

- Submit as many cases as you like

- Enjoy fast sympathetic peer review and rapid publication of accepted articles

- Access all the published articles

- Re-use any of the published material for personal use and teaching without further permission

For information on Institutional Fellowships contact consortiasales@bmjgroup.com

Visit casereports.bmj.com for more articles like this and to become a Fellow 